Cuadernos de Filología Clásica. Estudios Latinos

ISSN: 1131-9062

https://dx.doi.org/10.5209/cfcl.64893

\title{
Eneas en México. Recreaciones épicas de la llegada de Hernán Cortés ${ }^{1}$
}

Antonio Río Torres-Murciano²

Recibido: 25/03/2019 / Aceptado: 11/06/2019

Resumen. El propósito de este artículo es estudiar cómo la llegada de Hernán Cortés a Cozumel en febrero de 1519 fue celebrada en los poemas épicos quinientistas acerca de la conquista de México, que oscilan entre el realismo lucaneo adoptado por la Araucana de Alonso de Ercilla y la ficcionalización del relato de las crónicas según el modelo de la Eneida.

Palabras clave: Virgilio; Lucano; Alonso de Ercilla; Francisco de Terrazas; Gabriel Lobo Lasso de la Vega; Antonio de Saavedra Guzmán.

\section{[en] Aeneas in Mexico. Epic recreations of the arrival of Hernán Cortés}

\begin{abstract}
This paper is aimed at studying how Hernán Cortés' arrival to Cozumel in February 1519 was celebrated in sixteenth-century epic poems on the conquest of Mexico, which oscillate between the Lucanean realism adopted by Alonso de Ercilla's Araucana and the fictionalization of the account of the chronicles following the model of the Aeneid.

Keywords: Virgil; Lucan; Alonso de Ercilla; Francisco de Terrazas; Gabriel Lobo Lasso de la Vega; Antonio de Saavedra Guzmán.
\end{abstract}

Sumario. 1. Introducción; 2. Precedentes épicos; 3. Fuentes cronísticas; 4. Francisco de Terrazas; 5. Gabriel Lobo Lasso de la Vega; 6. Antonio de Saavedra Guzmán; 7. Conclusión.

Cómo citar: Río Torres-Murciano, A., «Eneas en México. Recreaciones épicas de la llegada de Hernán Cortés», en Cuad. Filol. Clás. Estud. Lat. 39.1 (2019), 69-92.

\section{Introducción}

La figura de Hernán Cortés no fue comparada con la de Eneas desde los primeros tiempos del descubrimiento del Nuevo Mundo, como lo fue la de Colón ${ }^{3}$, ni mereció

1 Este artículo es producto del proyecto «Edición crítica y estudio de Nuevo Mundo y Conquista de Francisco de Terrazas», financiado por la Dirección General de Asuntos del Personal Académico de la Universidad Nacional Autónoma de México (DGAPA-PAPIIT IN403318). Los resultados de la investigación que aquí se expone in extenso fueron en parte adelantados en el Coloquio «500 Años del Desembarco de Hernán Cortés» (Ciudad de México, 6-9 de mayo de 2019).

2 Universidad Nacional Autónoma de México, antonio_rio@enesmorelia.unam.mx (ORCID 0000-0001-5796-6699).

3 De manera implícita en la la carta de Pedro Mártir de Angleria al cardenal Ascanio Sforza (29 de abril de 1494) que habría de constituir el capítulo 2 de la primera de las Décadas, cuando se compara la división del territorio de la Española entre varios reyezuelos con la que Eneas y los suyos encontraron a su llegada al Lacio: Varios ibi 
ser equiparada a la del troyano en las crónicas más difundidas de la conquista de México ${ }^{4}$ La representación del conquistador como nuevo Eneas o Eneas de México, que habría de llegar hasta Alfonso Reyes ${ }^{5}$, se halla, en cambio, en los cuatro epopeyas cortesianas del siglo XVI -el inacabado Nuevo Mundo y Conquista de Francisco de Terrazas (ca. 1570-1580), la Primera parte de Cortés Valeroso y Mexicana (Madrid, Pedro Madrigal, 1588) y la Mexicana (Madrid, Luis Sánchez, 1594) de Gabriel Lobo Lasso de la Vega y el Peregrino indiano (Madrid, Pedro Madrigal, 1599) de Antonio de Saavedra Guzmán-, que aludieron a hechos y personajes de la Eneida cuando no la hicieron objeto de una imitación más sostenida que, como se verá, fue menos frecuente de lo que podría pensarse. La posibilidad de recrear literariamente según el modelo de Virgilio los episodios recabados de las fuentes cronísticas se vio, en efecto, limitada por el debate contemporáneo acerca de la pertinencia de introducir ficciones poéticas en la épica histórica, que propició que, frente a los ensayos virgilianos favorables a estas, persistiera una pretensión de historicidad de raigambre lucanea que, para la épica de Indias, encontraba apoyo añadido en el colosal precedente constituido por la Araucana de Alonso de Ercilla. En las páginas que siguen intentaremos mostrar cómo esta tensión entre la herencia de Lucano y la de Virgilio se deja percibir en las diversas recreaciones que estos cuatro poemas épicos ofrecen de la accidentada llegada de la flota de Cortés a las costas Cozumel, de la que este año se ha cumplido el quinto centenario.

\section{Precedentes épicos}

El problema de la proporción que debe guardar la verdad con la poesía en la épica histórica, que Jerónimo Sempere planteó en los comienzos mismos del cultivo de este género en la España del XVI al anunciar en el argumento de su Carolea (Valencia, Juan de Arcos, 1560) que «se lleva cuenta más con la verdad de la historia que con el poético estilo», se manifiesta por primera vez como tensión entre propósito de veracidad y voluntad de imitación literaria en el Carlo famoso de Luis Zapata (Valencia, Juan Mey, 1566) ${ }^{6}$. Si la segunda de estas aspiraciones fue reconocida expresamente por el propio Zapata en su Libro de cetrería - «procuré imitar con el Carlo famoso que hize en 13 años a las Eneidas de Virgilio» (ms.7844 BNE, 6v-7r)-, la primera fue escrupulosamente salvaguardada en el mismo Carlo famoso mediante el curioso expediente de señalar al margen con asteriscos las ficciones justificadas por el vene-

esse reges, hosque illis atque illos his potentiores inueniunt, uti fabulosum legimus Aeneam in uarios diuisum reperisse Latium, Latinum puta Mezentiumque Turnum et Tarchonem, qui angustis limitibus discriminabantur, et huiuscemodi reliqua per tyrannos dispartita (Angleria 1530, 6v).

4 La comparación no se encuentra en la Conquista de México de Francisco López de Gómara ni en la Historia verdadera de la conquista de la Nueva España de Bernal Díaz del Castillo. Sí está, y con claro propósito de Überbietung, en un pasaje de Gonzalo de Illescas señalado por Reynolds (1962, 260): «Y, pues cosas de menos cuenta y valor las encarecieron tanto los autores antiguos, y no acabamos de engrandecer a Homero, y a Virgilio y a otros poetas que alabaron a un Aquiles, Ulises, Eneas ¿qué fuera si para Hernando Cortés hubiera un Homero o un Virgilio o, si no, un Tito Livio?» $(1573,211 \mathrm{r}-211 \mathrm{v})$.

5 En su «Moctezuma y la Eneida mexicana», ensayo fechado en 1957 (Reyes 1981, 451-457).

6 Acerca de cómo mediante la reiterada tematización de esta dicotomía se llega a desarrollar una teoría de la épica histórica en los prólogos de las epopeyas, vid. Vega (2010) y Kohut (2014: 37-39). 
rable ejemplo de los poetas antiguos ${ }^{7}$. No es, pues, de extrañar que el primer pasaje así marcado sea aquel en que se relata la tormenta que arroja la flota de Carlos V a las costas de Inglaterra cuando estaba ya cerca de España (1.9-1.38.4), muestra palpable de virgilianismo en lo estructural y en lo formal. El modelo es, por supuesto, la tempestad que en el libro 1 de la Eneida (34-156) desvía la escuadra de los enéadas hacia Cartago cuando estos estaban a punto de alcanzar las anheladas costas de Italia ${ }^{8}$; la acción comienza, como en la Eneida, in medias res $^{9}$, y el resultado del desvío provocado por la tormenta, descrita con numerosos rasgos virgilianos ${ }^{10}$, es la historia de amor de Carlos V con María Tudor, que, al igual que la de Eneas con Dido, amenaza el cumplimiento del deber del héroe hasta que se produce una intervención divina para ponerle $\mathrm{fin}^{11}$. La pretensión de historicidad no le impidió, en efecto, a Zapata introducir en este momento una maquinación sobrenatural convenientemente cristianizada, llevando la imitación virgiliana a un extremo al que no había llegado en la previa narración de la tempestad. No hay, en efecto, en esta una trama que responda al desencadenamiento de los vientos por Eolo a instancias de Juno (Aen.1.34-86) ${ }^{12}$

7 No tiene desperdicio a este respecto la nota del impresor al lector: «Los cuentos que verás en este libro, las ficciones y fábulas debes agradecer infinito, pues con mucha diligencia y cuidado fueron para te recrear inventadas. De las cuales quien deseare disculpa no podrá ser de nadie disculpado, pues los poetas antiguos y muchos historiadores han usado lo semejante. Estos defiendan su causa primero, y, cuando no puedan, nuestro Carlo famoso holgará de ser con ellos culpado [...]. Y, por más convencer a los ingenios delicados que no perdonarán a nuestro Carlo lo que en otros alaban, va puesta en cada ficción esta señal * en la margen donde comienza y acaba». El texto del Carlo famoso, que citamos por la edición príncipe con la ortografía y la puntuación modernizadas, puede consultarse en Terrón Albarrán (1981) y en Vilá (2009), y el del Libro de cetrería en Terrón Albarrán (1979, CXVIII) y en Rodríguez Cachón $(2013,120)$.

8 La función narrativa de la tormenta como causa de que el héoe se desvíe de su ruta, con la consecuente prolongación de una accidentado viaje por mar que parecía llegar a término, se remonta, como es sabido, al pasaje de la Odisea (10.28-45) en que los compañeros de Odiseo abren el odre de los vientos inmediatamente después de haber avistado Ítaca. Virgilio está en deuda, asimismo, con Apolonio de Rodas (4.1232-1238), como bien han señalado Cristóbal (1988:127) y Nelis (2001, 120-124).

9 La tormenta se fecha en 1522, cuando el héroe regresa, ya como emperador coronado, de Flandes a España, y los hechos anteriores desde la muerte de Felipe el Hermoso los narra retrospectivamente el propio Carlos a Enrique VIII en cuatro cantos (3-6) como había narrado sus hazañas Eneas a Dido en dos (Aen. 2-3), durante un banquete al que no le falta ni un bardo como Blento (2.58-60), cuyo canto está obviamente inspirado en el del Jopas que ameniza el festín ofrecido a Eneas en Cartago (Aen.1.740-756).

10 Como son la bienaventuranza de los muertos en la guerra pronunciada por Carlos (1.20-21) igual que por Eneas (Aen.1.94-101) -y antes por Odiseo (Od.5.306-312)-, los «montes de agua» (1.13.2) -versión del aquae mons de Virgilio (1.105) que parece apuntar a un uso directo del texto latino por parte de Zapata, toda vez que en Hernández de Velasco $(1555,2$ r) la metáfora ha sido desmantelada por una traducción más bien prosaica como «borrasca»-y el hiperbólico subir y bajar de las olas que alcanzan el cielo y descienden hasta dejar a la vista el fondo («el agua embravecida / se hendió por mil partes hasta el suelo / y fue en terribles valles descendida / que llegaban al centro desde el cielo», 1.14.1-4), arrastrando consigo las naves («por las olas arriba unas subían, y del cielo quedarse vían colgadas; / otras de arriba a plomo descendían», 1.153-5) como en la Eneida (fluctusque ad sidera tollit, Aen.1.103; hi summo in fluctu pendent; his unda dehiscens / terram inter fluctus aperit, furit aestus harenis, Aen.1.106-107); también el desembarco en Inglaterra reescribe escenas del desembarco de los enéadas en África, como son la procura de fuego y vituallas (1.50; Aen.1.174-ss.) y especialmente la subida del héroe a un peñasco para otear el mar (1.48; Aen.1.180-183). Vid. Mañas Núñez (2009). La rotura del mástil por la mitad durante la tormenta (1.24.6) parece haber sido tomada, en cambio, de la Odisea (5.313), en la traducción de Gonzalo Pérez (1556: 98r). La Eneida se cita por la edición de Mynors (1969).

11 Los paralelismos virgilianos concretos que presenta Zapata en el relato de los amores del emperador con la princesa pueden verse en Gómez Gómez (2006, 186-195) y en Río Torres-Murciano (2016, 91 n.21).

12 Hay, sí, una descripción de los vientos «de sus oscuras cárceles saltando» (1.10.2) en la que Mañas Núñez (2009: 183) ha identificado un eco del clauso uentorum carcere virgiliano (Aen.1.141), pero los vientos del Carlo famoso están muy lejos del grado de personificación que permite a los de la Eneida ser implicados como personajes en una trama divina. 
o a su subsiquiente apaciguamiento por obra de Neptuno (Aen.1.124-156), lo que le da al pasaje del Carlo famoso un matiz lucaneo perceptible desde el principio en la manera como se describen las señales del inminente cambio de tiempo ${ }^{13}$. Y este lucaneísmo se verá acentuado, sin que por ello desaparezcan los elementos descriptivos virgilianos, en la segunda gran tormenta de la épica histórica renacentista española, que no es otra que la de la Araucana de Alonso de Ercilla ${ }^{14}$.

La tempestad que, entre la primera y la segunda parte (15.67-16.19) de la Araucana (Madrid, Pierres Cosin, 1569 y 1578), se abate sobre la flota española enviada a Arauco desde el Perú, es, a diferencia de la del Carlo famoso, un acontecimiento histórico contado por Ercilla con garantías de testigo presencial. No faltan, sin embargo, ecos virgilianos y ovidianos, que se entremezclan con la sonora terminología náutica recabada de la experiencia (Cristóbal 1988, 136-138; Nicolopulos 2000, 2128), ni tampoco recuerdos de la borrasca soportada por César a bordo de la barca de Amiclas en la Farsalia (5.560-677). La influencia de este pasaje, apuntada por Janik (1960, 100), ha sido subestimada por Nicolopulos (2000, 22-23), que echa en falta en Ercilla los presagios de mal tiempo presentes en Lucano (5.540-550); remiten, sin embargo a este, además de la invocación del narrador al Padre Eterno (16.9.5-8) -que, como bien ha notado Cristóbal (1988, 137), es reescritura piadosa del blasfemo apóstrofe de César a los dioses (Luc.5.654-656)-, la confusión de los elementos (16.5), que amenazan con volver al caos (Luc. 5.634-636), la mención de Neptuno (15.56.5) más como metonimia por el mar (Luc.5.621) que como personaje (Aen.1.124-147) y, en general, la supresión de la intriga divina virgiliana como desencadenante de la tormenta; intriga que se sustituye, además, en la Araucana por la misma fuerza que la había sustituido en la Farsalia. En efecto, la causa de la tempestad no es en Ercilla una intervención sobrenatural como la llevada a cabo por Juno en Virgilio, sino la Fortuna («Fortuna, que en el bien jamás fue estable, / turbó el cielo de nubes, mudó el viento, / revolviendo la mar desde el asiento», 15.67.6-8), como lo era en Lucano según aseveración de César (quaerit pelagi caelique tumultu / quod praestet Fortuna mihi, 5.592-593 $)^{15}$. La diferencia estriba en que en la Araucana es

13 Los cambios atmosféricos descritos a César por Amiclas en la Farsalia de Lucano (5.541-550), los ha resumido Zapata en tres endecasílabos (1.9.1-4), a los que ha hecho seguir una reescritura inequívoca del nec placet incertus qui prouocat aequora delphin, (Luc.5.572): «los delfines saltando podían verse / que comenzaban ellos ya a mostrarse» (1.9.5-6). La Farsalia se cita por la edición de Duff (1928), modificando ocasionalmente la ortografía y la puntuación.

14 En la Carolea de Sempere la turbación provocada en el mar por el paso de la Discordia, que viaja hacia Francia en la barca de Caronte, se describe con ecos de Lucano, pero en una sola estrofa («escóndense delfines donde llega, / el mar turbó el influjo de la luna; / movió tanta discordia en elementos [...]», 5.28.5-7). En el ámbito de la épica romancesca o caballeresca inspirada en Ariosto se encuentran ya tormentas en los cantos 1, 30 y 32 de la Segunda parte del Orlando de Nicolás Espinosa (Zaragoza, Pedro Bernuz, 1555) y en los cantos 12 y 13 de El verdadero suceso de la famosa batalla de Roncesvalles de Francisco Garrido de Villena (Valencia, Juan Mey, 1555). En Espinosa (1.33-34) se perciben ecos de la orgullosa osadía de César frente a la tempestad (Luc.5.577593), y la incapacidad del piloto ante el furor de esta («la fiera tempestad el saber parte», 30.13.5) recuerda la del Amiclas lucaneo en análoga situación (artis opem vicere metus, Luc.5.645); Garrido narra, a su vez, una disputa entre los tripulantes de la nave y un piloto atemorizado por las señales de mal tiempo (13.64-65) que podría estar basada en la habida entre César y Amiclas (Luc.5.540-593).

15 Lerner (1998², 452 n.132), por cuya edición citamos el texto de la Araucana con ocasionales modificaciones en la ortografía o la puntuación, ha hecho notar como «el texto pone en función simultáneamente las múltiples acepciones de fortuna 'borrasca en el mar' y 'azar, hado' y también la inestable diosa». La ineficaz intervención de Eolo - que entra fugazmente en escena no para desencadenar la tempestad, sino para intentar frenarla- recuerda asimismo, por la disyuntiva establecida entre azar natural y designio divino («Eolo, o ya fue acaso o se doliendo / del afligido pueblo castellano», 15.76.1-2), pasajes lucaneos análogos (1.234-235; 2.7-13). Los 
el narrador el que realiza la atribución de causa, con lo cual no sólo se despeja la ambigüedad lucanea, sino que se da el primer paso para cristianizarla: será, en efecto, el mismo narrador quien, a la hora de relatar la salvación de la nave a bordo de la cual él viaja, subsuma los azares de la Fortuna bajo la providencia divina («más quiso Dios que $[\ldots] », 15.74 .1$; «mas Dios $[\ldots] /[\ldots]$ / hizo que $[\ldots] », 16.13 .5-7)$, de acuerdo con la síntesis medieval plasmada por Juan de Mena en su Laberinto ${ }^{16}$.

Lo específicamente lucaneo en este pasaje de la Araucana es, pues -como lo era en el del Carlo famoso- la ausencia de maquinaria sobrenatural que motive y ponga fin a la tormenta. El designio de Dios está, sí, por encima de todo, incluida la Fortuna, pero el control divino de los acontecimientos se agota en una suposición fundamental del narrador, sin que suscite una narración en doble plano -humano y sobrehumano- como la que era propia del género épico desde Homero ${ }^{17}$. Se trata de un lucaneísmo narrativo, nacido más del prurito de veracidad propio de la épica histórica que de una intención de crítica al imperio difícilmente concebible en Ercilla ${ }^{18}$, que configura la Araucana en su totalidad ${ }^{19}$; pero que, como se verá,

españoles no se encuentran, pues, exactamente «in the same position as Aeneas and his men in Aeneid 1, where Aeolus, having been bribed by Juno, releases the winds to wreak havoc on the Trojan fleet», como ha creído Kallendorf (2007: 89) a partir de un pasaje en el que, antes de dar comienzo a la narración de la tormenta, el dominio de Eolo sobre los vientos («el cual temiendo / que el mundo no arruinen los encierra / echándoles encima una gran sierra», 15.85.6-8) se describe con ecos del sometimiento al que, según Virgilio, los redujo Júpiter (maria ac terras caelumque profundum / quippe ferant rapidi secum uerrantque per auras; / sed pater omnipotens speluncis abdidit atris / hoc metuens, molemque et montis insuper altos / imposuit, 1.58-62), previamente notados por Lerner (19982: 449 n.108).

16 La relación de la Fortuna con la Providencia en la Araucana ha sido entendida como identidad -la Fortuna es una apariencia de la Providencia- por Caillet-Bois (1962) y como subordinación -la Fortuna es servidora de la Providencia- por Muñoz $(1969,15)$ y -con reservas acerca de la eficacia de la síntesis de ambos conceptos-por Janik (1969, 107-108) y por Held (1983, 175), con remisión a Juan de Mena en los cuatro casos. Acerca de la amplia influencia de este en Ercilla, vid. Lida de Malkiel $\left(1984^{2}, 500-512\right)$ y Nicolopulos $(2000,85-105,128$ 173).

17 Este doble plano de la narración es perfectamente perceptible en el pasaje de la Odisea que sirvió de modelo a Virgilio para la tormenta provocada por Juno: la borrasca que se abate sobre la balsa de Odiseo tras haber salido este de la isla de Calipso es desencadenada por Poseidón (5.282-296) y calmada por Atenea (5.382-387). Aún cuando Ercilla reescriba el tópico de la resolución de la tempestad mediante una intervención divina, como bien ha notado Vilà (2001, 610-611), las diferencias son notables.

18 Baste decir aquí que la caracterización de la Araucana como «épica de los vencidos» (Quint 1993, 157-185) en la línea de Lucano menosprecia el hecho de que en el poema de Ercilla opera ideológicamente -aun cuando no se materialice narrativamente en un relato a doble plano- la que Gregory (2006: 12-14) ha llamado «distinción mosaica» propia de la épica cristiana de cruzada: la parcialidad caprichosa de los dioses de Homero, que Virgilio había subsumido bajo el designio providencial de un hado sostenido por Júpiter, ha dejado paso en la Araucana no a una «providencia cruel» (Narducci 2002, 152-166) contra la que Lucano se había permitido los más irreverentes reproches -desde negar la injerencia divina en los asuntos humanos (Phars.7.445-455) hasta achacar a los dioses responsabilidad criminal en la calamitosa marcha de estos (Phars.8.800)-, sino a un Dios bueno que está del lado de los españoles $(A r .8 .67 .5-8 ; 9.5-6 ; 15.74 .1 ; 16.13 .5-8)$ contra los indios sostenidos por el el Diablo $(1.40-41 ; 9.10-11 ; 8.39,43,63 ; 12.4 .1)$, y que, aun cuando castiga a los suyos por haber pecado (1.69; 5.1-2; $8.4 ; 8.65 .5-8 ; 9.6 .6-8)$, lo hace en virtud de una inapelable teodicea absolutamente extraña a la Farsalia -sin perjuicio de que Ercilla dé cabida al reproche de la avaricia y crueldad de los conquistadores que fue fundamental en el debate contemporáneo acerca de la conquista, y que, como bien ha hecho ver Aracil Varón (2011), en tal contexto debe entenderse-; vid. Río Torres-Murciano (2018, 426 n.10, 441). Acerca de la confluencia entre lucaneísmo narrativo y virgilianismo político en la épica histórica española del XVI son imprescindibles los trabajos de Vilà (2001: 13, passim; 2003; 2006; 2010; 2011a; 2011b).

19 En la medida en que relata su historia de manera lineal -y no in medias res- y sin sobreponer narrativamente al plano humano un plano sobrenatural de manera continua -rasgos ambos que constituyeron argumentos fundamentales de la crítica a Lucano como historiador indigno del nombre de poeta desde el Satiricón de Petronio (118) hasta el tercero de los Discorsi del poema eroico de Torcuato Tasso (1824, 96-98) (Narducci 2002, 76), y que, por eso mismo, fueron vistos con buenos ojos por los épicos que hacían profesión de veracidad histórica- 
no iba a ser asumido sin más por sus imitadores. La multiplicidad de los modelos antiguos, reconocida por el propio don Alonso al asociar la tempestad que había zarandeado la barca de Amiclas con las sufridas por Ulises en la Odisea y por Eneas en la Eneida -para afirmar que la padecida por él mismo en Chile las ha sobrepujado a todas ${ }^{20}$ - dejaba abierta la posibilidad de ensayar diversas combinaciones. Hubo, en efecto, autores que, aun sin dejar de componer épica histórica ni de imitar la Araucana, abandonaron el lucaneísmo ercillesco y extremaron la imitación virgiliana hasta el punto de introducir intrigas sobrenaturales para motivar narrativamente no ya acontecimientos inventados, como había hecho Luis Zapata con los amores de Carlos V y María Tudor ${ }^{21}$, sino hechos consignados en las fuentes historiográficas. En el ámbito de la épica de Indias, y sin perjuicio del papel fundacional que con respecto a esta le cupo a la Araucana, fue esto lo que sucedió con la recreación poética de una tormenta, la que se abatió sobre la escuadra de Hernán Cortés durante su travesía de Cuba a México, que, como a continuación se mostrará, comenzó a ser progresivamente virgilianizada desde la primera noticia que de ella se dio en una obra impresa.

\section{Fuentes cronísticas}

Don Alonso de Ercilla participó en los acontecimientos que cantó, pero esta circunstancia es excepcional en el panorama de la épica histórica hispánica ${ }^{22}$. Más habitual fue que los poetas tomaran como fuente el texto de una crónica en prosa, como hizo Zapata en su Carlo famoso ${ }^{23}$. Así, las cuatro epopeyas del siglo XVI sobre la conquista de México siguen todas la Conquista de México de Francisco López de Gómara (Zaragoza, Agustín Millán, 1552) ${ }^{24}$. En esta se encuentra el relato del temporal que se desencadenó sobre la armada de Hernán Cortés, recién partida de Cuba con rumbo a Yucatán, el 18 de febrero de 1519:

Ercilla toma como modelo narrativo -que no ideológico- a Lucano y no a Virgilio; vid. Río Torres-Murciano (2018, 429-431).

20 «No la barca de Amiclas asaltada / fue del viento y del mar con tal porfía, / que, aunque de leños frágiles armada, / el peso y ser del mundo sostenía. / Ni la nave de Ulises, ni la armada / que de Troya escapó el último día / vieron con tal furor el viento airado, / ni el removido mar tan levantado» (16.10). Nótese que el sobrepujamiento da aquí a la alusión lucanea un sentido nuevo con respecto al que le habían conferido quienes la habían traído a colación para elogio de la pobreza tranquila de Amiclas (Luc.5.515-531) desde Dante (Par.67-69) -en pos del cual había acogido el motivo en la poesía castellana Juan de Mena (Lab.227.5-8) (Lida de Malkiel 1984², 501$505)-$.

21 El matrimonio entre ambos llegó a capitularse (Beltrán y Rózpide y Blázquez y Delgado-Aguirre 1920-1925, vol.1, 490) cuando María era tan sólo una niña y la diferencia de edad entre los prometidos habría hecho completamente imposible el nacimiento de un amor como el que se describe en el Carlo famoso.

22 Excepción análoga es la constituida por la Historia de la Nueva México (Alcalá, Luis Martínez Grande, 1610) de Gaspar de Villagrá. Vid. López-Chávez (2016).

23 Las fuentes historiográficas seguidas por este fueron, de hecho, varias, aunque Terrón Albarrán (1981, XIV-XVIII), ha demostrado que la pauta se la dio el manuscrito de la Crónica del emperador Carlos $V$ de Alonso de Santa Cruz, dada a la imprenta por Beltrán y Rózpide y Blázquez y Delgado-Aguirre (1920-1925).

24 La deuda de Terrazas con Gómara, estudiada por Marrero-Fente (2007, 163-165), fue advertida ya por Amor y Vázquez (1962: 402), que posteriormente identificó la Conquista de México como fuente del Peregrino indiano $(1966,30)$ y de la Mexicana $(1970, x x)$. Con respecto al Cortés valeroso, en el que «Gómara» es expresamente mencionado junto con «otros» que han escrito acerca de las costumbres de los indios (1.29.3), vid. PullésLinares $(2005,38-39)$. 
La primera noche que se partió Fernando Cortés y que comenzó de atravesar el golfo que hay de Cuba a Yucatán, y que ternía pocas más de sesenta leguas, se levantó nordeste con recio temporal; el cual desrotó la flota; y así, se derramaron los navíos y corrió cada uno como mejor pudo. Y por la instrucción que llevaban los pilotos de la vía que habían de hacer, navegaron y fueron todos, salvo uno, a la isla de Acuzamil, aunque no fueron juntos ni a un tiempo (cap.10; Millares Ostos 1988, 19).

La noticia procede, sin duda, de la relación de Andrés de Tapia dada a la luz por García Icazbalceta, como puede verse por los paralelismos textuales ${ }^{25}$ :

E luego que se desabrazó de la isla, dio en su armada un temporal que derrotó los navíos, e por la instrucción que les habié dado de por do habién de navegar aportaron todos a una isla pequeña que en la mar se halló, cerca de la tierra firme, a quien los indios della llaman Aquçamil, e de todos los navíos no faltó mas de uno, de que después diremos (García Icazbalceta 1866, 555).

Es, en efecto, Tapia el único testigo presencial que se detiene a narrar un episodio que Bernal Díaz del Castillo se limita a evocar cuando achaca al «mal tiempo» la pérdida del timón de la nave capitaneada por Francisco de Morla (cap. 25; Serés 2011, 95). Ni Bernardino Vázquez de Tapia ni Francisco de Aguilar lo mencionan en sus respectivas relaciones (Gurría Lacroix 1972, 27; 1980, 66), y tampoco se encuentra rastro de él en la carta del cabildo de Veracruz (Delgado Gómez 1993, 119). Sí aparece, en cambio, en la primera noticia que de la expedición de Cortés se divulgó a través de la imprenta, aunque en una versión notablemente diferente de la que Andrés de Tapia proporcionó a Gómara. Se trata del De nuper sub D. Carolo repertis insulis simulque incolarum moribus de Pedro Mártir de Angleria (1521, 24-25), que, en un párrafo que en la primera edición conjunta de las Décadas pasó a formar parte del capítulo 6 de la Década 4, expone así la arribada de la flota española a la isla de Cozumel:

Ventum sequuntur eundem ab angulo Cubae ultimo ad Occidentem quem primo Franciscus Fernandez, mox Ioannes Grisalua; ad prospectum insulae sacrificiorum, de qua mentionem feci, deueniunt. Insperatus acer turbo captare terram uetuit, uersis illos uestigiis ad Cozumellam Iucatanae orientalem fera tempestas transportauit. Portum habet unicum haec insula, cui nomen Sancti Ioannis portae Latinae indiderunt (Angleria 1530, 59r).

Lo aquí dicho extraña porque la idea de que una tormenta desvió a los españoles hacia Cozumel cuando ya habían avistado la isla de Sacrificios, frente a San Juan de Ulúa, choca con el testimonio unánime de las fuentes. Si la carta de Veracruz se limita a decir que «a la primera tierra que llegaron fue la isla de Coçumel» (Delgado Gómez 1993, 119), Francisco López de Gómara asevera que, tras el temporal, todas

25 Acerca de la utilización de la relación de Tapia por Gómara en otros pasajes vid. Gurría Lacroix (1969; 1979, XIII-XIV), y Millares Ostos (1988, XXI-XXIII, LII). 
las naves salvo una se reunieron en Cozumel (Acuzamil) «por la instrucción que llevaban los pilotos de la vía que habían de hacer»; y que esta isla, y no el litoral de San Juan de Ulúa, había sido el destino previsto de la travesía es algo que deja perfectamente claro Bernal Díaz del Castillo cuando afirma que, antes de salir de Cuba, Cortés «mandó al piloto que llevaba en el navío que le aguardase en la punta de San Antón, para que allí se juntase con todos los navíos para ir en conserva hasta Cozumel» (cap.25 ; Serés 2011, 94). No otros habían sido los derroteros de Francisco Hernández de Córdoba y de Juan de Grijalva, predecesores de Cortés -el segundo de los cuales descubrió Cozumel, que llamó Santa Cruz-ni diversas las instrucciones dadas al respecto a Cortés por Diego Velázquez: «porque con ayuda de Nuestro Señor lleguéis todos juntos a la isla de Cozumel, Santa Cruz, donde será vuestra derecha derrota y viaje» (Martínez 1990, 50). ¿Cómo se explica, pues, que Pedro Mártir, después de haber afirmado que los de Cortés se habían hecho a la mar desde Cuba siguiendo «el mismo viento» (uentum [...] eundem) que antes habían seguido Córdoba y Grijalva, pretenda que fue un inesperado desvío provocado por una tempestad la causa de que, invirtiendo la ruta (uersis [...] uestigiis), llegaran a Cozumel? La información recibida por el milanés pudo haber sido en este punto equivocada o malinterpretada ${ }^{26}$; con todo, ¿no cabrá identificar aquí un primer ejemplo de cómo la tormenta del libro 1 de la Eneida informó la narración del temporal que se abatió sobre la escuadra cortesiana en el canal de Yucatán? Llama, desde luego, la atención el hecho de que en Pedro Mártir, al comienzo mismo del relato de la empresa de Cortés, los españoles se vean desviados por un temporal de San Juan de Ulúa, el emplazamiento en el que tiempo después habrán de fundar la Villa Rica de la Vera Cruz, de modo similar a como, al comienzo de la Eneida (1.34ss.), los troyanos de Eneas se vieron desviados de las costas de Italia, lugar predestinado a la fundación de Lavinio -y, más adelante, a la de Roma-, por una tempestad que, obligándolos a invertir la ruta, los arrojó, dispersados, a las costas de África. Bien es cierto que no tenemos en el pasaje del de Angleria una referencia inequívoca, aun cuando no expresa, a la Eneida como las que en él son habituales ${ }^{27}$, pero no por ello dejan de ser dignos de nota los paralelismos implícitos ${ }^{28}$. Veremos a continuación cómo el

26 Las fuentes de Pedro Mártir para la conquista de México fueron las informaciones que Cortés, sus hombres y los oficiales enviados a México por la Corona le proporcionaron por escrito desde allá o de palabra al regresar, según él mismo afirma en el capítulo 9 de la Década $5(1530,81 \mathrm{v})$. La noticia sobre la tormenta pudo haberle sido suministrada por Antón de Alaminos, Francisco de Montejo y Alonso Hernández Portocarrero, enviados por Cortés desde Veracruz en 1519 -pero no por Tapia, que no regresó a España hasta 1528-. Vid. Aracil Varón $(2016,22)$.

27 Los ciguanos (1.7), los habitantes de Ciamba (3.4) y los de la isla Española en general (7.10) son parangonados por sus rostros pintados con los agatirsos (Aen.4.146), las privaciones pasadas por los hombres de Diego de Nicuesa durante la expedición a Veragua (2.10) y por los de Colón durante el cuarto viaje (3.4) con las penalidades de Aqueménides (Aen.3.588-691), la migración de los de Matininó a la Española (3.7) con las peregrinaciones de Dido y de Eneas, el establecimiento de los españoles en las islas descubiertas (3.9) con el de los tirios en Libia, la fecundidad metafórica del Océano que «pare» nuevas tierras (7.1) a la fecundidad fabulosa de la puerca albana (Aen.3.388-393), ciertas aves prodigiosas aparecidas en Camará (7.10) a las harpías (Aen.3.210-258), y las insanae uoces de los adivinos piaches (8.8) a las de la Sibila de Cumas (Aen.6.77.102); además, la forma en que Pedro Mártir se refiere a la avaricia de los españoles en 7.1 (auri dira fames, 1530, 91v) evoca las célebres palabras con las que execró Virgilio la codicia de Poliméstor (auri sacra fames, Aen.3.57). Pero en sólo tres casos de entre estos $(1.7,2.10,3.4)$ se refiere Angleria expresamente a Virgilio -mediante un adjetivo (Maroniani Agathyrsi, Achaemenide Vergiliano, Vergiliani Achaemenidis, 1530, 16r, 35v, 43r) y sin consignar obra ni pasaje-.

28 La idea de desvío por inversión de la ruta presente en uersis uestigiis se expresa en le Eneida con el mismo verbo (Libyae uertuntur ad oras 1.158), y sigue una referencia al puerto africano (insula portum / efficit 1.159-160) 
color virgiliano que en Pedro Mártir pudo haber sido efecto de una reminiscencia involuntaria se incrementó, ya como consecuencia de una imitación intencionada, en las sucesivas recreaciones literarias de la tormenta y del subsiguiente desembarco de Cortés producidas por la épica quinientista.

\section{Francisco de Terrazas}

El primero en tratar la conquista de México en un poema épico tomando la crónica de López de Gómara como fuente fue don Luis Zapata, que hizo espacio al relato de la hazaña de Cortés en cinco cantos del Carlo famoso (11.55-62; 12.13-110; 13.1$44 ; 14.38-129 ; 15.1-10)^{29}$. No explotó a propósito de la tormenta las posibilidades de imitación virgiliana que le llevaron a introducir intrigas divinas en otros lugares de su obra o a hacer que, en la misma parte de esta dedicada a México (12.73), el náufrago, Jerónimo de Aguilar hablara como el Aqueménides del libro 3 (601-606) de la Eneida (Río Torres-Murciano 2016, 88-91), sino que se limitó a poner en verso con escasas variaciones la prosa de Gómara:

La primer noche que iba atravesando

de Cuba a Yucatán el golfo ondoso

se levantó un nordeste venteando

que desrotarse fue a las naos forzoso.

Así esparcidas fueron, lugar dando

al temporal más que ellas poderoso,

y en Acuzamil, isla allí oportuna,

al fin las naos llegamos, excepto una (12.26).

Habrá que esperar a Francisco de Terrazas - primer poeta que proyectó consagrar a la conquista de México una epopeya entera, que quedó inacabada a su muerte, acaecida hacia 1580 (Baudot 1988: 1086), y fue trasmitida en forma fragmentaria mediante las citas incluidas en el manuscrito de la Sumaria relación de las cosas de la Nueva España de Baltasar Dorantes de Carranza (1604) (10 $^{30}$ para encontrar un tratamiento más literario no de la tormenta en sí, sino de un lance ocurrido durante esta -la pérdida del timón de la nave de Francisco de Morla por efecto de un golpe de mar- acerca del cual las fuentes difieren. López de Gómara afirma que «el capitán Morla se echó a la mar atado a una soga, y a nado tomó el timón, y lo subieron y asentaron en su lugar como había de estar» (cap.10; Mi-

que podría haber perfilado el portum habet unicum haec insula de Mártir. Además, los dos términos empleados por este para denominar el temporal (turbo, tempestas) habían sido usados por el Mantuano para denominar la tempestad sufrida por los enéadas en (tempestas 1.377, turbo 1.511).

29 Acerca del anacronismo en que incurrió Zapata al poner la narración de la conquista en boca de Francisco de Montejo, enviado por Cortés desde Veracruz a la corte de España, vid. Río Torres-Murciano (2016, 88 n.13). La deuda del Carlo famoso con la Conquista de Gómara ha sido puesta de manifiesto en las notas de Medina (1916) y en las añadidas a estas por Reynolds (1984), así como en el estudio introductorio de Terrón Albarrán (1981: XXVIII-XXXIV, XXXVIII).

30 El manuscrito, utilizado por García Icazbalceta (1884) para publicar por primera vez los fragmentos de Nuevo mundo y Conquista y dado después íntegramente a la imprenta por Ágreda y Sánchez (1902), pertenece actualmente a la Universidad de Texas en Austin (Benson Latin American Collection, JGI 664). 
ralles Ostos 1988, 20), mientras que Bernal Díaz del Castillo asevera que Cortés llegó a Cozumel más tarde que Pedro de Alvarado «por causa que un navío, en que venía por capitán Francisco de Morla, con el mal tiempo se le saltó el gobernalle, y fue socorrido con otro gobernalle de los navíos que venían con Cortés» (cap.25; Serés 2011, 95) ${ }^{31}$. Tanto Zapata como Terrazas siguen a Gómara, pero, donde el primero había preferido ceñirse una vez más a la narración del cronista $^{32}$, encontró el segundo ocasión para introducir una amplificación poética de la materia histórica en la que es posible rastrear la imitación de la épica antigua. Lo más reseñable a este respecto es el apóstrofe que dirige Morla a Neptuno antes de lanzarse al agua para recuperar el timón ${ }^{33}$ :
«Cruel Neptuno», dice, «a quien es dado
de estos salados reinos el gobierno,
que hoy contra esta flota te has aunado
con furiosas cuadrillas del infierno,
en vano ha de salir lo concertado,
que el Dios de las alturas sempiterno
quiere a despecho de tus crueles manos
dar ayuda y favor a sus cristianos» (fr. 12.17-24).

Podría quizás pensarse que Morla está invocando a un Neptuno que, como personaje del poema - e identificado, como dios pagano, con un demonio- habría provocado la tormenta a fin de impedir que los españoles lleguen a México. No hay, sin embargo en los fragmentos de Nuevo Mundo y Conquista nada que nos permita suponer que funcionara en este poema una maquinaria sobrenatural divino-demoníaca, ni mucho menos que Terrazas le hubiera asignado a Neptuno en el desencadenamiento de la tormenta un papel similar al que Virgilio le había otorgado a Juno. El tono narrativo de las partes conservadas de Nuevo Mundo y Conquista es más bien ercillesco, es decir, más lucaneo que virgiliano. El mismo apóstrofe de Morla a Neptuno parece modelado sobre la increpación de César a los dioses en la Farsalia (5.654-656) reescrita piadosamente por Ercilla (16.9.5-8), quien, al igual que Lucano (5.621), se refiere a Neptuno más como metonimia por el mar que como personaje con plena capacidad de actuación. Y, si Ercilla (16.5) había seguido a Lucano (5.634-636) al describir hiperbólicamente la tempestad como confusión caótica de los cuatro ele-

31 La versión de Bernal es, con todo, producto de una corrección efectuada sobre otra muy similar a la de López de Gómara después de haberla aceptado en un primer momento, puesto que en el manuscrito de Guatemala se tachó «y volvieron por la mar en busca del gobernalle y le hallaron y le pusieron en su lugar, con que luego navegó la nao cuyo era» (19v), vid. Barbón Rodríguez $(2005,63)$. Dicha corrección fue hecha antes del envío a Madrid del manuscrito perdido que sirvió para la edición impresa llevada a cabo por fray Alonso Remón (1532, $16 \mathrm{v})$, puesto que en en esta figura la versión corregida.

32 «Aquella noche tempestuosa tanto / de la nave de Morla el viento fiero / y el mar le rebataron entre tanto / de la mano el timón al timonero. / Hizo señal la nao, y amainó en tanto / Cortés, y esperó, que iba él delantero, / y sobre ella fue con la capitana / y aguardó al resplandor de la mañana. / Y con la nueva luz en más bonanza / se demostró la mar de antes tan brava, / y vieron sobre el agua a su ordenanza / que suelto acá y allá el timón andaba; / por él se echó al mar Morla, y sin tardanza / le sacó y le suplió adonde faltaba, / y estas dos naos que así se detuvieron / a la postre a allegar a la isla fueron» (12.27-28).

33 El texto de Nuevo Mundo y Conquista se cita por la edición de Castro Leal (1941), con referencia a números de fragmento y de versos. 
mentos, Terrazas le pone fin describiendo el retorno de cada uno de ellos a su lugar por efecto del heroísmo de Morla:

\author{
«iMorla!» diga la Fama, Morla asiente, \\ borre trofeos, batallas, vencimientos, \\ que otros vencieron hombres solamente, \\ Morla a los invencibles elementos; \\ los cuales, viendo así tan fácilmente \\ estorbar solo un hombre sus intentos, \\ confusos se retiran aire y fuego, \\ y dejan cielo y aguas en sosiego (fr. 12.57-64).
}

Parece pues que Terrazas, quien en en otro lugar compara al cacique Canetabo (fr.15.132) con el Polifemo virgiliano (Aen.3.655-665) -siguiendo la línea trazada por Zapata al identificar a Jerónimo de Aguilar con Aqueménides (Romano Martín 2017; Río Torres-Murciano 2016, 91-95)- se inclinó, en cambio, en su recreación literaria de la tormenta por el modelo lucaneo previamente seguido por Ercilla. Iba a ser Gabriel Lobo Lasso de la Vega quien aprovechara plenamente las oportunidades que para imitar la Eneida ofrecía el episodio del temporal recabado de Gómara.

\title{
5. Gabriel Lobo Lasso de la Vega
}

La Primera parte de Cortés valeroso y Mexicana de Gabriel lobo Lasso de la Vega consta de doce cantos de los que los diez primeros se ubican narrativamente en la tradición lucanea de Ercilla, pues no hay en ellos una maquinaria sobrenatural que se superponga al relato histórico (Río Torres-Murciano 2018, 427-431). El gusto del poeta madrileño por Virgilio se deja, sin embargo percibir claramente en su tratamiento de la tempestad, que hace confluir con la causalidad lucanea numerosos ecos de la Eneida. La causa del cambio de tiempo es, como en Ercilla -y en Lucano, según César- la Fortuna, a cuyos vaivenes se dedica el proemio moral de cuño ariostesco que abre el canto $2(1-2)$ y precede inmediatamente a la narración del temporal («cerca asiste del bien la desventura, / del estado apacible la mudanza; / no hay cosa estable, firme ni segura», $2.1 .1-3)^{34}$, anticipado por alteraciones de la luz celeste que recuerdan las descritas por Amiclas a César en la Farsalia $(5.541-550)^{35}$. Pero el relato de la borrasca está lleno de evocaciones virgilianas,

34 La doble atribución a la Fortuna y al hado que encontramos más adelante en el Cortés valeroso («hado nocivo», 2.4.1; «Fortuna», 2.8.5; «Fortuna y hado», 2.30.3) es, por lo demás, frecuente en Lucano (e.g. 2.699-701; $6.612-615 ; 7.88-89,646-647)$, si bien es cierto que, a propósito de la tempestad del libro 5, el poeta neroniano prefirió poner en boca de César el doblete dioses-Fortuna (uectorem non nosse tuum, quem numina numquam / destituunt, de quo male tum Fortuna meretur / cum post uota uenit, 581-582), que es también recurrente en la Farsalia (e.g. 5.59; 7.796; 8.706-708). El texto del Cortés valeroso se cita por la edición de Pullés-Linares (2005), modificando en ocasiones la ortografía y la puntuación.

35 «Comienza el claro cielo a marañarse / y a turbarse la luz de las estrellas, / y el fulminoso Norte a recatarse / en dar la claridad de sus centellas, / ven las lucientes Ursas retirarse, / cubiertas de terror sus frentes bellas, / y de un color horrible y ceniciento / ocupado el celeste movimiento» (2.5). La retirada de las Osas, que nunca se ponen, puede haberse inspirado no tanto en el texto latino de Lucano, que habla de estrellas fijas sacudidas (summis etiam quae fixa tenentur / astra polis sunt uisa quati, 5.563-564), como en la traducción de Martín Laso 
tomadas ya del texto latino de la Eneida, ya de la traducción de Gregorio Hernández de Velasco ${ }^{36}$. Si el bramido del viento del norte («con gran violencia horrísono bramando, / al mar se arroja el Aquilón furioso», 2.6.1-2) parece clara reescritura del primero (stridens Aquilone procella (Aen.1.102) ${ }^{37}$, las descripciones de la oscuridad de la noche («y un tenebroso, escuro y negro velo / cierra la noche, tremen mar y cielo», 2.6.7-8) y de los rayos y truenos («y de espantosos truenos el ruido / comienza, y de relámpagos la priesa», 2.7.6-7) son evidentemente deudoras de cómo la segunda vierte los pasajes virgilianos referidos a la una (ponto nox incubat atra, 1.89; "una cerrada y tenebrosa noche / tiende sobre el turbado mar sus alas», $4 \mathrm{r}$ ) y a lo otros (intonuere poli, et crebris micat ignibus aether, 1.90; «rebrama el cielo de un polo al otro / con gran frecuencia de espantosos truenos / [...] con relámpagos espesos», 4r). E igualmente se observa la dependencia de la traducción de Hernández de Velasco en los versos con que Lasso describe el subir y bajar de las naves zarandeadas por las olas:

Andaban por el ancho mar vagando
los ágiles navíos sin consuelo,
cuál sin vela o trinquete levantando
en las hinchadas olas alto vuelo;
cuál con el fin postrero agonizando
ve la herviente arena y bajo suelo (2.12.1-6).

De Velasco ha tomado Lasso la hinchazón de las olas, ausente en Virgilio ( $h i$ summo in fluctu pendent; his unda dehiscens / terram inter fluctus aperit; furit aestus harenis, 1.106-107) y la traducción de terram por «suelo», junto con la ubicación de esta última palabra al final del endecasílabo:

Penden algunos en las altas olas,

y en el hinchado mar andan subidos;

a otros l'agua del mar hondo abierta

les muestra por entre ola y ola el suelo.

Hierve la arena $(4 \mathrm{v})$.

La estrecha cercanía al texto de la Eneida o al de su traducción toledana cede, en cambio, cuando se amplifica el insequitur clamorque virum virgiliano (1.87), vertido por Velasco como «comienza en esto un gran clamor de gente» (4r) con

de Oropesa (1541), que habla de estrellas fijas que aparentan caerse («aun las mesmas estrellas que están fijas en los altos cielos parecía que se caían», 67v). De que Gabriel Lobo Lasso utilizó la versión de Oropesa en otros lugares de su obra hemos tenido noticia gracias a Jorge Luis Torres Magallón.

36 Las traducciones de Hernández de Velasco son, en realidad, tres, pues en cada una de las tres ediciones impresas en Toledo (Juan de Ayala, 1555; Juan de Ayala, 1574; Diego de Ayala, 1577) se introdujeron variaciones, a veces tan poco desdeñables como la que añadió a la tercera la versión del preproemio de la Eneida (ille ego qui quondam [...]) que falta en la primera y en la segunda. Seguimos el texto de la tercera modernizando ortografía y puntuación, sin perjuicio de remitir a las otras cuando sea oportuno.

37 Lasso ha ofrecido aquí una traducción más fiel del Aquilone del original (Aen.1.102) que las que pueden encontrarse en Hernández de Velasco, que lo tradujo primero por «cierzo» $(1555,2$ r) y después por «Norte» $(1574$, 5r; 1577, 4v). 
elementos procedentes de la Araucana, como son las promesas hechas por los navegantes aterrados (Ar.15.71.2) o la mezcla contra natura de la tierra con el cielo (Ar.16.3.5-8) provocada por la tempestad, así como el sustantivo «alarido» (Ar.15.75.5):
El alarido, llanto y vocería, el fácil prometer con voz rompida y mísero lamento que se oía de la gente medrosa y afligida; con el bramar del viento parecía que la celeste esfera, desasida, con la inferior terrestre se juntaba, según la confusión manifestaba (2.9).

La imitación de la Eneida no se agota, por lo demás, en la narración de la borrasca, sino que, tras la hazaña de Francisco de Morla, recogida tal como la consignó Gómara, y el accidentado desembarco en Cozumel se suceden las escenas virgilianas. Mientras los hombres agotados prenden fuego y disponen comida y bebida (2.2627), de manera muy parecida a como lo habían hecho los enéadas al arribar a Cartago (Aen.1.174-179), Cortés otea el mar en busca de las naves perdidas desde lo alto de un «peñasco» («sobre un corvo peñasco levantado / [...] / se sube, y la turbada vista arroja / por el agua con íntima congoja», 2.29-5-8) llamativamente similar a aquel scopulum sobre el que se había subido Eneas en indéntica situación (Aen.1.180-183), traducido por Velasco con el mismo término que el empleado por Lasso («en esto Eneas sube en un peñasco / y mira del mar ancho en todas partes / cuan lejos puede divisar su vista», $6 \mathrm{v})^{38}$-sin que, por supuesto, ni Gómara ni ningún otro cronista hagan mención de semejante hecho-. Después de la comida, el capitán español dirige a sus hombres una arenga que no dejará de resultar familiar a los lectores de la Eneida (1.198-207):
«Caros amigos, cuyo esfuerzo al hado contrario hará bastante resistencia, cuyo valor mil veces se ha mostrado contra el hórrido Marte y su violencia, pues habéis tantas glorias alcanzado por la divina y alta providencia, no el viento fiero ni la mar airada os turbe, pues su furia es ya pasada.

Que por este escabroso y mal camino, por las ignotas vías que abriremos, nos lleva nuestro próspero destino, do un rico y nuevo mundo ganaremos» (2.33-34.1-4).

38 El ascenso al peñasco había sido utilizado ya por Zapata en el Carlo famoso (1.48). Vid. supra n. 10. 
Desde la interpelación inicial -en la que el «amigos caros y leales» de Velasco (7r) ha sido preferido al menos efusivo socii del original (Aen.1.98)- hasta la referencia al «escabroso y mal camino» -deudora del «fragoso y duro / camino» con que Velasco (7v) vertió el per tot discrimina rerum virgiliano (Aen.1.204)-, pasando por la idea de que el recuerdo de los peligros superados en el pasado debe funcionar como acicate contra la desgracia presente -el o passi grauiora de Virgilio (Aen.1.199), que tradujo fielmente Velasco por «en más graves peligros ya probados» (7v)-y por la exhortación a la confianza en el auxilio divino -el dabit deus his quoque finem (Aen.1.199) que en la versión toledana se volvió, con notable libertad, «confiad en los dioses inmortales» $(7 \mathrm{v})$-, todo aquí recuerda el célebre discurso dirigido por Eneas a los suyos en la costa de África, rubricado por un no menos célebre comentario del narrador (talia uoce refert, curisque ingentibus aeger / spem uultu simulat, premit altum corde dolorem, Aen.1.208-209) que se encuentra asimismo, pasado por el tamiz de Hernández de Velasco ${ }^{39}$, en el Cortés valeroso:

Estas y otras razones les decía, copiosas de esperanzas y consuelo, y aunque de alegre rostro se fingía, llena está el alma de ansia y desconsuelo (2.36.1-4).

En la Mexicana de 1594, versión corregida y aumentada del Cortés valeroso y Mexicana publicado por Lasso en 1588, se encuentran tanto los ecos virgilianos en la narración de la tormenta $(2.7-8,18,21)$ como el ascenso de Cortés al peñasco (2.48) y la coda del narrador a la arenga (2.59.1-4), mientras que esta (2.52-58), sin perder su raíz virgiliana, ha sufrido modificaciones considerables ${ }^{40}$. En la narración de la tormenta ha intensificado, en cambio, Lasso el virgilianismo, reescribiendo un conocido pasaje de la Eneida que no había dejado huella en el Cortés valeroso. Se trata de aquel en el que Eneas, helado ante el desencadenamiento de la tempestad (extemplo Aeneae soluuntur frigore membra, Aen.1.92), lamenta su desgracia con una queja (o terque quaterque beati, / quis ante ora patrum Troiae sub moenibus altis contigit oppetere [...], Aen.1.94ss.) modelada sobre la bienaventuranza pronun-

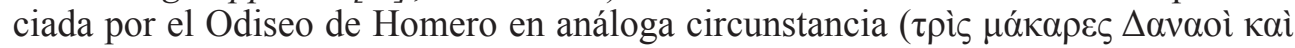

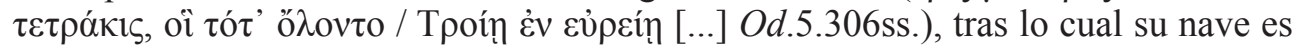
embestida por el viento y las olas (talia iactanti stridens Aquilone procella / uelum aduersa ferit, fluctusque ad sidera tollit, Aen.1.102-103) como lo había sido la de

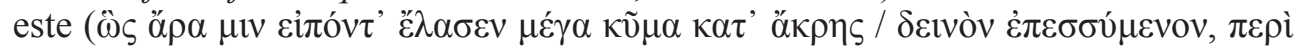

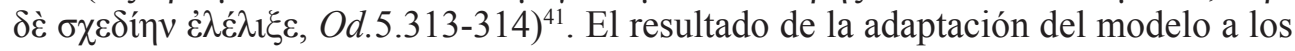

39 «Estos consuelos y otros les propone, / y, combatido de cuidados grandes, / finge esperanza en la aparencia y rostro, / mas en el corazón siente grande ansia» (7v).

40 Modificaciones que se explican en su mayor parte por el sentido de cruzada que, como ya advivirtió Amor y Vázquez (1967, 187-188; 1970, XXXVII-XXXVIII, LI-LIII), se ha incrementado en la Mexicana con respecto al Cortés valeroso por efecto de la influencia de la Jerusalén liberada de Tasso. Nótese, por ejemplo que la Mexicana (2.57.4) dice «do el árbol de Cristo plantaremos» donde el Cortés valeroso (2.34.4) decía «do un rico y nuevo mundo ganaremos ».

41 Hernández de Velasco traduce el pasaje como sigue: «Córtale en aquel punto un miedo helado / los miembros turbadísimos a Eneas; / lamenta y gime lastimosamente, / y, al cielo puestas juntas ambas manos, / comienza d'esta suerte a lastimarse: / «iOh tres y cuatro veces fortunados / los que tan gran merced del cielo hubieron: / que, a vista de sus padres degollados, / junto al troyano muro perecieron! / Oh hijo de Tideo, a quien los hados 
antecedentes y al celo católico de Cortés, que hace que el lamento de raigambre clásica se vea precedido por una devota súplica al Todopoderoso ( $« \mathrm{Oh}$ autor de toda

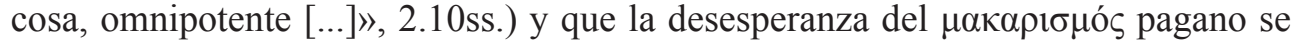
compense con una profesión de resignación y esperanza cristianas, es el siguiente:

Sintió el pío Cortés que un frío hielo por sus helados miembros se esparcía

$[\ldots]$

y con gemido oculto lastimoso

mirando al cielo dice fervoroso (2.9.1-2, 7-8).

$[\ldots]$

«iOh muchas veces bien afortunado

yo, si cuando rompí los hierros duros,

que en Cuba el ofendido Adelantado

me puso y guarda de velados muros,

fuera en las aguas mísero anegado,

cuyos medios tomé por más seguros,

que, aunque muerte sin gloria sé que fuera,

no el inocente pueblo padeciera!

Mas, pues el justo cielo pïadoso, me guardó para ver tan triste suerte, esto conviene, no hay que estar quejoso, pues esto es lo mejor si bien se advierte.

$\mathrm{Y}$, si en alto coro fulminoso está dispuesto que mi celo acierte a echar al ángel vano de su asiento, no hay que temer el líquido elemento».

Diciendo aquesto, con furor lo embiste de agua un empellón por la siniestra; óyese un lastimoso clamor triste y junto al cielo y a la nao se muestra (2.13-15.1-4).

La intensificación de la influencia virgiliana es, de hecho, un rasgo que caracteriza a la Mexicana de 1594 con respecto al Cortés valeroso de 1588, y que, tras haber sido anunciado desde el primer verso - «canto las armas y el varón famoso», que sustituye el «canto el furor de Marte sanguinoso» de la primera versión-, se hace patente en el tratamiento de la tormenta (Río Torres-Murciano 2018: 449-452). Porque en la Mexicana no sólo ha tomado Lasso de Virgilio la descripción del mal tiempo o los discursos del héroe, sino también la ubicación del temporal en el conjunto del relato y -lo que es aun más relevante- la causalidad sobrenatural que lo provoca. Si

/ mayor valor que al griego resto dieron, / ¿por qué yo no teñí el campo troyano / con mi sangre vertida por tu mano? / [...] ». / Así decía, y una gran borrasca / que vino retronando d'hacia el Norte / hiere la vela con vehemencia horrible, / y sube al cielo las bravosas olas» $(4 \mathrm{r}-4 \mathrm{v})$. 
el Cortés valeroso comenzaba con una descripción etnográfica del imperio mexicano (1.10-47) deudora de la descripción de los araucanos hecha por Ercilla (1.6-46), seguida de la narración de los primeros pasos de Cortés y de las expediciones que precedieron a la suya (51-61), la Mexicana comienza in medias res con el temporal. Y, si este era provocado en el Cortés valeroso por la Fortuna, en la Mexicana lo es por Plutón, protector sobrenatural de los mexicanos que, al ver la flota española surcar el mar, da rienda suelta a su indignación:
Daba Cortés al favorable viento
y al mexicano golfo vela hinchada,
y las naves con presto movimiento,
blanca espuma del mar alzan salada,
cuando Plutón, con grave sentimiento,
revuelve en la memoria fatigada
el daño inevitable del abismo,
y así comienza a hablar consigo mismo (1.22).

No se le habrán escapado al lector de la Eneida las evidentes concomitancias con el inicio de esta ${ }^{42}$ :
Vix e conspectu Siculae telluris in altum
uela dabant laeti, et spumas salis aere ruebant,
cum Iuno, aeternum seruans sub pectore volnus, haec secum (1.34-37).

La reescritura de la Juno virgiliana como Plutón, que se remonta a la Jerusaleń liberada de Tasso (4.1ss.), le ha servido a Lasso para establecer un vínculo entre el Diablo y la ciudad de México (1.6-10) similar a aquel que unía a la Saturnia virgiliana con la ciudad de Cartago (Aen.1.12-22). Siguen, además, un monólogo de Plutón (1.23-26) modelado sobre el pronunciado por Juno antes de provocar la tormenta (Aen.1.37-49) y una visita de Plutón a Neptuno (1.27-43) modelada sobre la de Juno a Eolo (Aen.1.50-80), tras lo cual se abate sobre los españoles la tempestad provocada por las fuerzas demoníacas hasta que Dios le pone fin mandando a San Miguel a alentar a Cortés (2.31-36) como Júpiter había mandado a Mercurio a alentar a Eneas en Virgilio (Aen. 4.219-277), y a preparar las tierras mexicanas para el combate entre el bien y el mal (2.37) como Mercurio había preparado el terreno a los enéadas en Cartago (Aen. 1.297-305). De este modo, Gabriel Lobo Lasso no sólo configuró en su segunda epopeya sobre la conquista de México una doble maquinaria sobrenatural divino-demoníaca de estirpe tassesca, sino que lo hizo llevando al extremo las posibilidades de recreación virgiliana que encontró en el episodio de la tormenta y en la subsiguiente llegada de Cortés a las riberas de Cozumel.

\footnotetext{
42 Paso que Velasco tradujo como sigue: «daban al diestro viento alegres velas, / y del salado mar saltar hacían / blancas espumas con las naos herradas, / cuando la airada Juno, refrescando / en su memoria le herida eterna, / consigo comenzó a hablar dest'arte» $(2 \mathrm{r}-2 \mathrm{v})$.
} 


\title{
6. Antonio de Saavedra Guzmán
}

Frente al alto nivel de ficcionalización a que la imitación de Virgilio y de Tasso llevó a Gabriel Lobo en la Mexicana, el Peregrino indiano de don Antonio de Saavedra Guzmán -cuarta y última (y única concluida) de las epopeyas del XVI sobre la conquista de México- se alinea expresamente con la historicidad contra los ornamentos de la poesía ${ }^{43}$. Nada tiene, pues, de chocante que su principal modelo para la tormenta (1.73-108) haya sido la Araucana ${ }^{44}$. De esta toma pasajes no sólo descriptivos -ya transponiéndolos de manera muy literal ${ }^{45}$, ya amplificando los lugares correspondientes de Ercilla ${ }^{46}$ - sino también narrativos - como aquel en que Eolo, desempeñando la función contraria a la que le había asignado Virgilio en la Eneida, intenta contener a Bóreas, que se le escapa $(1.82 ; A r .15 .76)$-, e incluso la alusión a los modelos épicos romanos con la pretensión de haberlos dejado atrás ${ }^{47}$ :

\author{
No estuvo tan gozoso aquel troyano, \\ capitán valeroso, que se vido \\ contrastado del viento y mar insano, \\ quando libre escapó de ser perdido, \\ ni aquel supremo rey tan soberano, \\ que en la barca de Amiclas fue metido, \\ quando, como Cortés, se vio librado \\ de la grave tormenta y mar airado (1.107).
}

43 El autor se refiere en el prólogo a su obra como «historia» y «manjar de verdad» (Rodilla León 2008, 63), e insiste en esta idea a lo largo del poema $(1.50-51 ; 9.127-128 ; 10.28 ; 11.68)$, hasta llegar a presentarse al rey Felipe III como el primer historiador nacido en México («que soy en México nacido, / donde ningún historiador ha habido», 11.13.1-7). Particularmente interesante es el pasaje en que -a imitación quizás del Cortés valeroso («dad de la Caballina lleno el vaso, / a quien otro valor y esfuerzo canta», 1.7.3-4), inspirado a su vez en Persio (nec fonte labra prolui caballino, prol.1) - el rechazo de la ficción poética se expresa con la mención de Hipocrene, la «fuente del Caballo» habitada por las musas («no lleva el ornamento de invenciones, / de Ninfas, Cabalinas, ni Parnaso», 10.28.1-2). El texto del Peregrino indiano se cita por la edición de Rodilla León (2008) modernizando la ortografía y modificando en ocasiones la puntuación.

44 La preocupación del piloto al percibir las señales de la inminente tormenta (PI 1.74.5-8) no se halla en Ercilla sino en Lucano (5.539-556), pero Saavedra puede haberla tomado de los pasajes en que Lasso había extendido la inquietud a la tripulación entera (CV 2.5; Mex. 2.6). Sí parece proceder directamente de Ercilla (15.80.3-4) la incapacidad del piloto para gobernar la nave durante la tormenta (PI 1.84.7-8), presente antes en Lucano (5.6456) y en Ovidio (Met.11.492-494).

45 Notable es el caso en que Saavedra utiliza el término «racamenta» para denominar el anillo con el que las vergas se sujetan a los mástiles («y con la furia ya la racamenta / no gobernaba con la gran tormenta» 1.81.7-8»), reescribiendo un pasaje de Ercilla que, según anota Lerner $\left(1998^{2}, 455\right.$, n.150), es la más temprana documentación literaria de dicho término («y así la racamenta no corría», 15.75.8), así como el pasaje en que el ruido del cordaje -motivo que se remonta en última instancia al stridorque rudentum virgiliano (Aen.1.87)- se describe («las gúmenas, del Céfiro estiradas, / rechinan, y las jarcias oprimidas», 1.84.1-2) sin perder de vista el lugar correspondiente de la Araucana («las gúmenas y jarcias rechinaban / del turbulento Céfiro estiradas», 15.82.12).

46 Al motivo de las instrucciones que los atribulados marineros se gritan entre sí (1.78.7-8, 79.7-8, 80.1-2, 85.14) -reconducible, como ha notado Cristóbal $(1988,127)$ a Ovidio (Met.11.482-483) y empleado reiteradamente por Ercilla (15.70.7-8, 72.1-2, 80.5-6, 81.1-6; 16.8.7-8)- ha añadido Saavedra los lamentos, también en estilo directo, de quienes se acuerdan de sus familias (1.87.4-8), y ha amplificado el motivo ercillesco de las promesas devotas $(A r .15 .71 .2 ; 16.8 .5)$ haciendo que los propios personajes las expliciten (1.93) y añadiendo inmediatamente una reflexión moral (1.94-95).

47 Ha suprimido Saavedra la alusión a la Odisea, que sí estaba en la Araucana (16.10, cit. supra n.20) para quedarse con las tormentas de la Eneida y de la Farsalia -a la cual vuelve a referirse en 32.2.1-4-. 
Pero ya Amor y Vázquez (1966) hizo ver que, que, aun cuando el Peregrino indiano se basa en la Conquista de López de Gómara, y a pesar de que lleva una aprobación del cronista de Indias Antonio de Herrera, su autor fue menos historiador y más poeta de lo que pensaron él mismo y algunos de sus lectores, como Baltasar Dorantes de Carranza (Ágreda y Sánchez, 1902, 203) y Francisco Javier Clavijero (Cuevas, 1964, XXIx). Por cuanto atañe al temporal hay que notar que, si bien se achaca primeramente a la Fortuna («mas la Fortuna, que en el bien no dura, / mudó el alegre tiempo en desventura», 1.73.7-8), siguiendo de cerca a la Araucana («Fortuna, que en el bien jamás fue estable / turbó el cielo de nubes, mudó el viento», 15.68.6-7), enseguida se plantea como efecto de una maquinación diabólica:

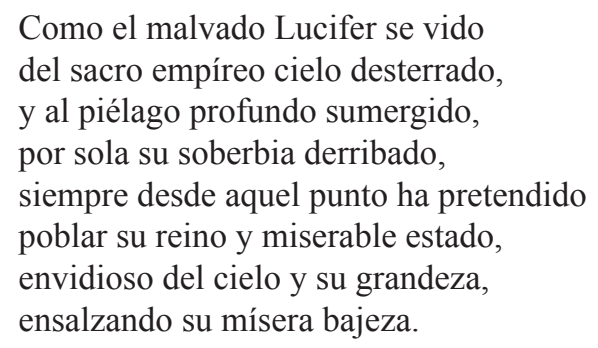

Como el malvado Lucifer se vido del sacro empíreo cielo desterrado, $\mathrm{y}$ al piélago profundo sumergido, por sola su soberbia derribado, siempre desde aquel punto ha pretendido poblar su reino y miserable estado, envidioso del cielo y su grandeza, ensalzando su mísera bajeza.

Luego que conoció el divino fruto que la pujante armada prometía, con libertar las almas del tributo que el príncipe malvado poseía, por no perder el mísero estatuto de aquel oscuro reino y monarquía, convocó sus legiones y potencia para que le hiciesen resistencia.

Movió a los poderosos quatro vientos que unánimes viniesen conjurados, saliendo de sus cóncavos asientos, de toda su potencia alimentados. Furiosos, arrogantes y violentos, indómitos, pujantes y mezclados, de suerte que, la flota sumergida, deshecha fuese y del gran mar sorbida (1.75-77).

Los vientos cumplen, sí, el encargo de Lucifer («no fueron en cumplirlo perezosos [...]», 1.78.1ss.), pero será la Fortuna la que, tras un ruego dirigido por Cortés a Dios («dilata ya el castigo merecido, / al fin que la Fortuna ha encaminado, / donde espero, Señor, serás servido», 1.104.1-3), termine cediendo, al igual que ocurría en la Araucana $(15.74 .1 ; 16.13 .5-7)$, ante el designio divino favorable a los españoles, como ya el narrador lo ha anticipado: 
Irá Fortuna el rostro revolviendo, $\mathrm{y}$, sus vanos intentos contrastados, el Sumo Hacedor de tierra y cielo con mano liberal dará consuelo (1.99.5-8).

De este modo, Saavedra introdujo un principio de intriga sobrenatural vagamente constituida -sin parlamentos en estilo directo remontables a los monólogos de la Juno virgiliana ni identificación tassesca del Diablo con el dios pagano Plutón- que no sólo no tuvo continuidad a lo largo de su obra, sino que se desvaneció ya en el mismo relato de la tormenta ${ }^{48}$. Desde el punto de vista de la causalidad, el Peregrino indiano permaneció en la línea lucaneo-ercillesca aun después de una fugaz intervención del Diablo que debió de haberle sugerido a Saavedra la Mexicana de Gabriel Lobo Lasso ${ }^{49}$.

Hay, en efecto, en el Peregrino indiano varios pasajes que prueban que Saavedra hizo a Lasso objeto de una imitación textual continuada comparable sólo al modo en que usó repetidamente a Ercilla y a Terrazas ${ }^{50}$. Si a Terrazas debe Saavedra, además de la reivindicación de los méritos de los conquistadores con la intención de reclamar la recompensa debida a sus descendientes (5.9-17; cf. Nuevo Mundo y Conquista fr. 20), el relato que de su cautiverio entre los mayas hace Jerónimo de Aguilar a Cortés (2.94-103; $N M C$ fr. 15.97-272) ${ }^{51}$ y el sermón catequético que le endereza este al calachuní de Cozumel (2.50-61, NMC fr. 13) ${ }^{52}$, proceden de Lasso la tormen-

48 Por lo demás, los dioses paganos son objeto de menciones pasajeras, pero más como metonimias o personificaciones al uso -Marte, Belona y Palas por la guerra, Apolo por el sol, etc.- que como personajes acabados (4.45, $69,76,86-87,518 ; 6.12,13,53 ; 9.50 ; 11.33 ; 16.53 ; 17.99 ; 19.53)$, papel que no desempeñan ni en el episodio de la bruja Tlantepucilama (9.113-116) ni en el sueño alegórico con que se honra a Felipe II (14.80). El tratamiento de estas figuras por Saavedra es, pues, muy similar al que les habían dado Ercilla en la Araucana y Lasso en los primeros diez cantos del Cortés valeroso (Río Torres-Murciano 2018, 430).

49 En el ámbito de la épica histórica española la figura del Diablo - presente ya, aunque fugazmente, en la Carolea de Jerónimo Sempere (5.6; 9.2; 19.21) y en el Carlo famoso de Zapata (20.103-21.18), había sido objeto de elaboraciones tassescas anteriores a la de la Mexicana en la Austríada de Juan Rufo (20.57-63; 21.6-13), publicada en 1584, y en el Cortés valeroso (12.86-90) -a las que hay que añadir, en el ámbito de la épica religiosa, la del Monserrate de Cristóbal de Virués (1.8-19), publicado en 1587-. Vid. Río Torres-Murciano (2018, 437 n.48).

50 Basta un cotejo de los textos para ver que los ecos del episodio lucaneo de Ericto (6.670-718) notados por Romero Galván (1994, 121-123) en el episodio saavedriano de Tlantepucilama (9.98-115) han llegado a través del episodio ercillesco de Fitón (23.48-54, 80-82). Frente a los numerosos paralelismos que en Ercilla delatan una dependencia directa de Lucano (6.671-749; 9.700-838) - o, más exactamente, de la traducción de la Farsalia por Laso de Oropesa (1541, 84v, 135v-138r), sin perjuicio de la influencia del Laberinto de Juan de Mena (241-251) señalada por Lida de Malkiel $\left(1984^{2}, 505,508\right.$ n.53) y por Nicolopulos (2000, 128-173)-, nada en Saavedra permite suponer una relación semejante con el épico neroniano.

51 Aunque ha suprimido Saavedra las sonoras evocaciones virgilianas que en su modelo conformaban el retrato del cacique antropófago, restan el nombre de este -que no se encuentra en las fuentes cronísticas pero aparece como Canetabo en Terrazas (fr. 15.122, 170, 238) y Canebato en Saavedra (2.101.2)- y los demás paralelismos entre ambos autores señalados en Río Torres-Murciano (2016, 98-99). Lobo Lasso siguió, en cambio, en la Mexicana (3.22-23) la línea iniciada por Zapata en el Carlo famoso (12.73) al identificar a Aguilar con el Aqueménides de la Eneida (3.601-606) (Río Torres-Murciano 2016, 95-97).

52 Lo que permite aventurar que el banquete ofrecido a los españoles por la esposa del calachuní inmediatamente antes (2.44-49) - que quizás habría que remontar en última instancia al ofrecido a Eneas por Dido en Cartago (Aen.1.699ss.)- podría haber estado también en Nuevo Mundo y Conquista. Las posibilidades que Saavedra ofrece para reconstruir hipotéticamente el contenido del poema de Terrazas han sido notadas por Castro Leal (1941, XVII), Torre Villar (1987, XXXIII-XXXIV) y Cebollero (2009, 84). 
ta $^{53}$, los amores de Jorge de Alvarado con la india Xúchitl (10.54-65; CV 12.19-28; Mex.20.21-30) y la descripción de las armas del cacique Tabasco (6.25-30; CV 3.25-

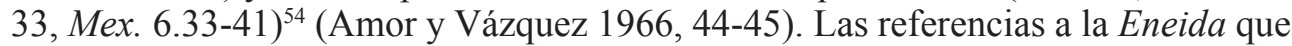
pueden espigarse en el poema de Saavedra son, en cambio, comparaciones eruditas pasajeras como las que se encuentran ocasionalmente en las crónicas, y no indicios de un seguimiento sostenido del texto latino o de su traducción española como el que hemos hallado en la Mexicana ${ }^{55}$.

\section{Conclusión}

El estudio de las sucesivas recreaciones de la llegada de Hernán Cortés a México en el Nuevo Mundo y Conquista de Francisco de Terrazas, el Cortés valeroso y la Mexicana de Gabriel Lobo Lasso de la Vega y el Peregrino indiano de Antonio de Saavedra Guzmán demuestra que en la épica cortesiana del Quinientos coexistieron a propósito de la imitación de los modelos clásicos dos tendencias, que sustancialmente son las mismas que entre las epopeyas de la conquista de Chile ejemplifican respectivamente la Araucana de Alonso Ercilla y el Arauco domado de Pedro de Oña (Lima, Antonio Ricardo, 1596): una que se remonta a Lucano a través de Ercilla y otra que hace confluir a Virgilio con Tasso en mayor o menor proporción ${ }^{56}$. El hecho de que la propensión lucaneo-ercillesca puede informar un poema claramente celebrativo, como es el de Saavedra ${ }^{57}$, y la constatación de que ambas tendencias pueden

53 La devota idea expresada por Cortés en su súplica durante la tempestad, cuando pide a Dios que haga recaer el castigo sobre él solo (1.103), se encontraba ya en la Mexicana (2.12), como notó Amor y Vázquez (1966, 44).

54 Parece en este caso que el texto seguido por Saavedra es más bien el del Cortés valeroso («espalda y pecho» 6.254, CV 3.25.1), al que probablemente se remontan también las «Cabalinas» de 10.28.2 (vid. supra n.43), mientras que la intervención del demonio para provocar la tempestad sólo ha podido proceder de la Mexicana. Es, pues, posible que ambos poemas hayan sido conocidos por Saavedra, de cuya cercanía al entorno de Lasso da indicio, como advirtió Amor y Vázquez $(1966,45)$, el hecho de que uno de los sonetos preliminares al Peregrino indiano sea obra de Jerónimo Ramírez, secretario del tercer marqués del Valle y prologuista de la Mexicana.

55 Las referencias a la Eneida en el Peregrino indiano son, además, palmarias, desde aquellas en que se parangona expresamente a Cortés con Eneas (1.107.1-4; 8.19) a la que compara el saco de México con el de Troya (19.53.1-2), pasando por aquella otra en la que el auxilio prestado por los de Xochimilco a los españoles es equiparado al hospedaje brindado por Dido en Cartago al troyano (19.80). Sólo en el doliente relato de Cabalacán («no quieras, capitán, que yo lastime / estas tiernas entrañas lastimadas / renovando un dolor que tanto oprime», 5.47.1-3) hay un eco textual implícito (infandum regina iubes renouare dolorem, Aen.2.3) -identificado por Méndez Plancarte $(1942,95)$ - que funciona más como alusión literaria propiamente dicha que como exemplum o cita docta. El símil de la flor tronchada por el arado (4.95) -que, como es sabido, cuenta con una larga tradición épica estudiada por Cristóbal (1992) y por Plagnard (2017)- debe más a la segunda égloga de Garcilaso (1250-1266) -del que Saavedra se reconoce deudor en otro lugar (18.52.7) al tomar prestado el célebre endecasílabo «ioh dulces prendas por mi mal halladas!» (Sonetos 10.1) (Méndez Plancarte 1942, 95)- que a Virgilio (Aen.9.69-71).

56 Nótese, sin embargo, que la tormenta relatada por Oña en el Arauco domado (3.75-4.21) es, tras las huellas de la Araucana, fundamentalmente lucanea, y que sólo después de esta entra en escena la máquina infernal tassescovirgiliana (4.66ss.). Huidobro (2017: 336-337) ha percibido esta duplicidad, si bien lo ha hecho entendiendo el virgilianismo y el lucaneísmo en un sentido más ideológico que narrativo.

57 Es cierto que en los reproches que hace a los españoles el Cabalacán de Saavedra (3.44.45) podrían identificarse ecos de las palabras del Galbarino de Ercilla (2.11-13) semejantes a los que se perciben en las del Quétzal de Terrazas (fr. 4.169-176), pero la credibilidad del personaje de Saavedra se ve socavada por su doblez (3.49-52, 72), y la única defensa expresa de los indios que se haya en el Peregrino indiano es la de los aliados texcocanos de Cortés (18.87-88), hecha en tono análogo al de la vindicación de los derechos de los descendientes de los conquistadores (15.5-17). Saavedra ha eliminando, además, los reproches que por su responsabilidad en la 
darse en momenos distintos en un mismo autor de perspectiva igualmente triunfalista, como ocurre en el caso de Gabriel Lobo ${ }^{58}$, invitan, sin embargo a mostrar cautela a la hora de emplear dicotomías ideológicas como la que opone a una épica de vencedores una épica de vencidos, transponiendo categorías empleadas en los debates recientes acerca de la Eneida y de la Farsalia a un contexto que, en realidad, estaba determinado por el debate quinientista acerca de la cabida que debía concederse a la invención poética en la épica histórica.

\section{Bibliografía citada}

Ágreda y Sánchez, J.M. de (1902), Baltasar Dorantes de Carranza. Sumaria relación de las cosas de la Nueva España, México, Museo Nacional.

Amor y Vázquez, J. (1962), «Terrazas y su Nuevo Mundo y Conquista en los albores de la mexicanidad», Nueva Revista de Filología Hispánica 16.3-4, 395-415.

Amor y Vázquez, J. (1966), «El peregrino indiano: hacia su fiel histórico y literario», Nueva Revista de Filología Hispánica 18.1-2, 25-46.

Amor y Vázquez, J. (1967), «Conquista y Contrarreforma: la Mexicana de Gabriel Lobo Lasso de la Vega», en Sánchez Romeralo, J. y Poulussen, N. (eds.), Actas del Segundo Congreso Internacional de Hispanistas, Nimega, Universidad de Nimega, 181-191.

Amor y Vázquez, J. (1970), Gabriel Lobo Lasso de la Vega. Mexicana, Madrid, Atlas.

Angleria, P.M. de (1521), De nuper sub D. Carolo repertis insulis simulque incolarum moribus, Basilea, s.e.

Angleria, P.M. de (1530). De orbe novo [...] decades, Alcalá de Henares, Miguel de Eguía.

Aracil Varón, B. (2011), «Ética y conquista en La Araucana (en torno a la muerte de Caupolicán)», en Alonso, M.N. y Alemany, C. (eds.), Diálogos para el Bicentenario, Concepción, Universidad de Concepción, 145-169.

Aracil Varón, B. (2016), «Yo, don Hernando Cortés». Reflexiones en torno a la escritura cortesiana, Madrid-Frankfurt, Iberoamericana-Vervuert.

Barbón Rodríguez, J.A. (2005), Bernal Díaz del castillo. Historia verdadera de la conquista de la Nueva España (Manuscrito «Guatemala»), México, El Colegio de México-UNAMDAAD-AECID.

Baudot, G. (1988), «Lupercio Leonardo de Argensola continuador de Francisco de Terrazas. Nuevos datos y documentos», Nueva Revista de Filología Hispánica 36.2, 1083-1091.

desairada situación de estos había hecho a Cortés Terrazas (fr. 20.127-192); y, al tratar el asedio de México, ha desmentido implícitamente la calumnia levantada contra el conquistador por fray Bartolomé de las Casas en la Brevísima relación de la destrucción de las Indias (Martínez Torrejón, 2013, 42-43), donde lo había acusado de cantar el famoso romance «Mira Nero de Tarpeya» durante la matanza de Cholula: «No como el cruel Nerón cuando se ardía / la desdichada Roma por su mano / [...] / que el benigno Cortés mucho sentía / la fuerza de tratar así al tirano» (19.88.1-2, 5-6).

58 La vindicación de la retribución debida a la prole de los conquistadores se agota en Lasso en el apoyo implícito a las pretensiones de los herederos de Cortés -su hijo don Martín y su nieto don Fernando, exiliados de la Nueva España a causa de la conjura que pasó a la historia con el nombre del primero-, que protegieron en Madrid al poeta con su mezenazgo. Y la defensa de la valía de los indios - expresa en el prólogo del Cortés valeroso (Pullés-Linares, 2005, 132-133) y enfatizada en la Mexicana mediante la adición de una "Apología en defensa del ingenio y fortaleza de los indios de la Nueva España» compuesta en prosa por el licenciado Jerónimo Ramírez- sirve al solo propósito de enaltecer los merecimientos del conquistador (Amor y Vázquez 1970, XXIV, XXXV-XXVI). 
Beltrán y Rózpide, R. y Blázquez y Delgado-Aguirre, A. (1920-1925), Crónica del Emperador Carlos V compuesta por Alonso de Santa Cruz, Madrid, Patronato de Huérfanos de Intendencia e Intervención Militares.

Caillet-Bois, J. (1962), «Hado y Fortuna en La Araucana», Filología 8.3, 404-420.

Castro Leal, A. (1941), Francisco de Terrazas. Poesías, México, Porrúa.

Cebollero, P. (2009), Discurso, retórica y agencia del criollo mexicano en Nuevo Mundo y Conquista de Francisco de Terrazas, Saarbrücken, VDM Verlag Dr. Müller.

Cristóbal, V. (1988), «Tempestades épicas», Cuadernos de Investigación Filológica 14, 125 148.

Cristóbal, V. (1992), «Una comparación de clásico abolengo y larga fortuna», Cuadernos de Filololgía Clásica. Estudios Latinos 2, 155-187.

Cuevas, M. (1964), Francisco Javier Clavijero. Historia antigua de México, México, Porrúa.

Delgado Gómez, A. (1993), Hernán Cortés. Cartas de relación, Madrid, Castalia.

Duff, J.D. (1928), Lucan. The Civil War, Cambridge, Harvard University Press.

García Icazbalceta, J. (1866), «Relación hecha por el señor Andrés de Tapia sobre la conquista de México», en Colección de documentos para la historia de México, 2, México, Antigua Librería, 554-594.

García Icazbalceta, J. (1884), «Francisco de Terrazas y otros poetas del siglo XVI», Memorias de la Academia Mexicana 2, 357-425.

Gómez Gómez, J.M. (2006), «Dos actualizaciones diferentes de los amores de Dido y Eneas. Luis Zapata de Chaves, Carlo Famoso, y Cristóbal de Mesa, Las Navas de Tolosa», Revista de Estudios Latinos 6, 185-200.

Gregory, T. (2006), From Many Gods to One. Divine Action in Renaissance Epic, Chicago, The University of Chicago Press.

Gurría Lacroix, J. (1969), «Andrés de Tapia y la Historia de la conquista de México escrita por Francisco López de Gómara», Memorias de la Academia Mexicana de la Historia 28.4, 342-351.

Gurría Lacroix, J. (1972), Relación de méritos y servicios del conquistador Bernardino Vázquez de Tapia, México, UNAM.

Gurría Lacroix, J. (1979), Francisco López de Gómara. Historia de la conquista de México, Caracas, Biblioteca Ayacucho.

Gurría Lacroix, J. (1980), Fray Francisco de Aguilar. Relación breve de la conquista de la Nueva España, Mexico, UNAM.

Held, B. (1983), Studien zur Araucana des Don Alonso de Ercilla, Frankfurt, Haag und Herchen.

Huidobro, M.G. (2017), El imaginario de la guerra de Arauco. Mundo épico y tradición clásica, Santiago de Chile, Fondo de Cultura Económica-Universidad Andrés Bello.

Illescas, G. de (1573), Segunda parte de la historia pontifical y católica, Salamanca, Vicente de Portonariis.

Janik, D. (1969), «Ercilla, lector de Lucano», en AA.VV., Homenaje a Ercilla, Concepción, Universidad de Concepción, 83-109.

Kallendorf, C. (2007), The Oher Virgil. Pessimistic Readings of the Aeneid in Early Modern Culture, Oxford, Oxford University Press.

Kohut, K. (2014), «La teoría de la épica en el renacimiento y el barroco hispanos y la épica indiana», Nueva Revista de Filología Hispánica 62.1, 33-66.

Laso de Oropesa, Martín (1541), La historia que escribió en latín el poeta Lucano trasladada en castellano, Lisboa, Luis Rodríguez.

Lerner, I. (1998²), Alonso de Ercilla. La Araucana, Madrid, Cátedra. 
Lida de Malkiel, M.R. (1984²), Juan de Mena poeta del prerrenacimiento español, México, El Colegio de México.

López-Chávez, C. (2016), Epics of Empire and Frontier. Alonso de Ercilla and Gaspar de Villagrá as Spanish Colonial Chroniclers, Norman, University of Oklahoma Press.

Mañas Núñez, M. (2009), «Poetica tempestas. La Eneida de Virgilio en el Carlo famoso de Luis Zapata», en Chaparro Gómez, C. et al. (eds.), Nulla dies sine linea. Humanistas extremeños: de la fama al olvido, Cáceres, Universidad de Extremadura, 175-196.

Marrero-Fente, R. (2007), «Alegorías de la historia: imitación épica y modelos historiográficos en Nuevo Mundo y Conquista de Francisco de Terrazas», RILCE 23.1, 157-167.

Martínez, J.L. (1990), Documentos cortesianos, 1, México, UNAM-FCE.

Martínez Torrejón, J.M. (2013), Fray Bartolomé de las Casas. Brevísima relación de la destrucción de las Indias, Madrid, Real Academia Española.

Medina, J.T. (1916), El primer poema que trata del descubrimiento del Nuevo Mundo. Reimpresión de la parte correspondiente del Carlo famoso de D. Luis Zapata, con un breve prólogo biográfico y cien compendiosas notas crítico históricas, Santiago de Chile, Imprenta Universitaria.

Méndez Plancarte, A. (1942), Poetas novohispanos. Primer siglo (1521-1621), México, UNAM.

Miralles Ostos, J. (1988), Francisco López de Gómara. Historia de la conquista de México, México, Porrúa.

Muñoz, L. (1969), «Ercilla, protagonista de La Araucana», en AA.VV., Homenaje a Ercilla, Concepción, Universidad de Concepción.

Mynors, R.A.B. (1969), P. Vergili Maronis opera, Oxford, Clarendon Press.

Narducci, E. (2002), Lucano. Un'epica contro l'impero, Roma-Bari, Laterza.

Nelis, D. (2001), Vergil's Aeneid and the Argonautica of Apollonius Rhodius, Leeds, Francis Cairns.

Nicolopulos, J. (2000), The Poetics of Empire in the Indies. Prophecy and Imitation in La Araucana and Os Lusiadas, University Park, The Pennsylvania State University Press.

Quint, D. (1993), Epic and Empire. Politics and Generic Form from Virgil to Milton, Princeton, Princeton University Press.

Plagnard, A. (2017), «“Como la blanca flor o roxo lirio». Variaciones portuguesas sobre el símil épico de la flor cortada», en Bognolo, A. et al. (eds.), Serenísima palabra. Actas del X Congreso de la Asociación Internacional Siglo de Oro (Venecia, 14-18 de julio de 2014), Venecia, Università Ca' Foscari, 287-299.

Pullés-Linares, N. (2005), Gabriel Lobo Lasso de la Vega. De Cortés valeroso y Mexicana, Frankfurt-Madrid, Vervuert-Iberoamericana.

Remón, A. (1632), Historia verdadera de la conquista de la Nueva España, Madrid, Imprenta del Reino.

Reyes, A. (1981), Obras completas, 21, México, Fondo de Cultura Económica.

Reynolds, W.A. (1962), «Hernán Cortés y los héroes de la Antigüedad», Revista de Filología Española 45, 259-271.

Reynolds, W.A. (1984), El primer poema que trata del descubrimiento y conquista del Nuevo Mundo. Reimpresión de las partes correspondientes del Carlo famoso de Luis Zapata. Nueva edición crítica por José Toribio Medina y Winston A. Reynolds, Madrid, José Porrúa Turanzas.

Río Torres-Murciano, A. (2016), «Polifemo en Yucatán. Variaciones sobre un episodio de la Eneida en la épica cortesiana del Quinientos», Cuadernos de Filololgía Clásica. Estudios Latinos 36.1, 85-106. 
Río Torres-Murciano, A. (2018), «La configuración de la maquinaria sobrenatural en la poesía épica de Gabriel Lobo Lasso de la Vega», Revista de Filología Española 98.2, 423-458.

Rodilla León, M.J. (2008), Antonio de Saavedra Guzmán. El peregrino indiano, MadridFrankfurt, Iberoamericana-Vervuert.

Rodríguez Cachón, I. (2013), «El Libro de cetrería (1583) de Luis de Zapata: estudio y edición crítica», tesis doctoral, Universidad de Valladolid.

Romano Martín, S. (2017), «Nuevo Mundo y Conquista de Francisco de Terrazas y la tradición virgiliana», Bulletin of Spanish Studies 94.6, 625-655.

Romero Galván, J.R. (1994), «Tlantepucilama. Una hechicera entre dos culturas», en Buxó, J.P. y Herrera, A. (eds.), La literatura novohispana. Revisión crítica y propuestas metodológicas, México, UNAM, 111-124.

Serés, G. (2011), Bernal Díaz del Castillo. Historia verdadera de la conquista de la Nueva España, Madrid, Real Academia Española.

Terrón Albarrán, M. (1979), Luis Zapata. Libro de cetrería. Facsímil del ms. 4219 de la Biblioteca Nacional de Madrid, Badajoz, Institución «Pedro de Valencia».

Terrón Albarrán, M. (1981), Luis Zapata. Carlo famoso. Facsímil de la edición príncipe de 1566, Badajoz, Institución «Pedro de Valencia».

Torre Villar, E. de la (1987), Baltasar Dorantes de Carranza. Sumaria relación de las cosas de la Nueva España, México, Porrúa.

Vega, M.J. (2010), «Idea de la épica en la España del Quinientos», en Vega, M.J. y Vilà, L. (eds.), La teoría de la épica en el siglo XVI (España, Francia, Italia, Portugal), Vigo, Academia del Hispanismo, 103-135.

Vilà, L. (2001), «Épica e imperio. Imitación virgiliana y propaganda política en la épica española del siglo XVI», tesis doctoral, Universidad Autónoma de Barcelona.

Vilà, L. (2003), «La épica española del Renacimiento (1540-1605): propuestas para una revisión», Boletín de la Real Academia Española 83, 137-150.

Vilà, L. (2006), «Épica, historia y la construcción de los mitos nacionales. La problemática de la teoría y la praxis de la épica culta en el siglo XVI (en Italia y España)», História e perspectivas $34,86-106$.

Vilà, L. (2009), Luis Zapata de Chaves. Carlo famoso, Bellaterra, Universidad Autónoma de Barcelona.

Vilà, L. (2010), «Fama y verdad en la épica quinientista española. El virgilianismo político y la tradición castellana del siglo XV», Studia Aurea 4, 1-35.

Vilà, L. (2011a), “"Compuesto de materia que es la verdad histórica». Virgilianismo político y escritura épica», en Vilà, L. (ed.), Estudios sobre la tradición épica occidental (Edad Media y Renacimiento), Bellaterra-Madrid, Universidad Autónoma de BarcelonaUniversidad Carlos III, 123-139.

Vilà, L. (2011b), «Vera cum fíctis. L'allégorie historique selon Servius et l'idée de l'epos», en Bouquet, M. y Méniel, B. (eds.), Servius et sa réception de l'Antiquité à la Renaissance, Rennes, PUR, 145-160. 